\title{
PROBLEMAS INTERGENERACIONES EN LA CONTINUIDAD DEL QUECHUA
}

\author{
INTERGENERATION PROBLEMS IN THE CONTINUITY OF \\ QUECHUA
}

\section{QICHWA SIMI RIMAKUNALLANPAQ ÑAWPA WIÑAYMANTA QIPA WIÑAYMANTA SASACHAKUYKUNA(1)}

\author{
Jesús Orccottoma Cárdenas ${ }^{(2)}$ \\ Universidad Nacional Mayor de San Marcos, Perú
}

Resumen: El problema central de reflexión es la discontinuidad de la transmisión del idioma quechua entre dos generaciones (padres/hijos). La pregunta desde la cual se parte es la siguiente: ¿por qué quienes saben quechua no enseñan a sus hijos este idioma? Hay una secuencia lógica del derrotero seguido: referencias históricas y las oportunidades perdidas, datos cuantitativos para ver su evolución, una introspección personal y la elaboración de las conclusiones.

Palabras Clave: Panandina, lengua franca, quechua hablante, identidad étnica, racismo, herencia colonial.

Abstract: The main topic of reflexion is the loss of transmission of Quechua between two generations (parents/children). The question the article starts with is: Why do native Quechua speakers doesn't teach their children its language? There is a logical sequence in the path that follows: historic references and lost opportunities, quantitative data to see the evolution of Quechua, a personal perspective and finally the elaboration of conclusions.

Key Words: Andes, lingua franca, Quechua speaker, ethnic identity, racism, colonial heritage.

(1) Traduccion: Martin Castillo Collado. Lengua Quechua / Cusco Collao

(2) Licenciado en Sociología en la UNMSM; estudios de Maestría en Sociología en la PUCP; y en Historia Andina en la Facultad Latinoamericana de Ciencias Sociales/FLACSO. Forma parte del staff de consultores de: MISEREOR, PPM y SASE CONSULTORES. Email: orccottoma@gmail.com 
Pisiyasqa yuyay: Kay qillqaqa yuyaychakun imaynan qichwa simi mana qatiqatilla taytakunamanta wawakunaman chayasqanmanta. Kay tapuywanmi qallarikun: Imaraykupitaq qichwata yachachkaspanku mana wawankuman yachachinkuchu. Chaykunamantan imaymanata qawachiwanchik, "chay rurananchikkuna mana rurasqanchikmanta", chanin yupaykunamantapas rikuchiwanchik, imaynas qichwa kawsay karqa chayta, imaynataq sapakamapas chaykunapi churapakunamantapas.

Yuyaychakuq simikuna: Qichwa, kikinchik kay, mana allin qawanakuy, saqiwasqanchikkuna. 


\section{Los puntos de partida y las huellas del pasado}

La mayoría de los estudios sociales, especialmente de corte histórico, afirman que la cultura andina careció de una escritura alfabética, es decir, fue una cultura ágrafa. De esta afirmación se desprende una gran tarea para los científicos sociales, cumplir con el reto de encontrar la otra parte de la historia andina, aquella que se encuentra invisible, la que no está escrita. Hay un sinnúmero de ejemplos, que dan cuenta de esta situación. Los primeros cronistas en la época de la conquista utilizaron como fuente principal la oralidad quechua, luego la escritura en castellano: al final las crónicas (medias verdades), fueron documentos oficiales que se utilizaron para el ejercicio de la dominación colonial, desde el comienzo hasta el final, como en el caso de Sarmiento de Gamboa: "como ya se señaló, Sarmiento escribió su historia específicamente para Francisco de Toledo con la finalidad de informarle de las costumbres, leyes e historias de los incas. Su Historia de los Incas fue una de las principales fuentes de información empleadas por Toledo en la reorganización y reubicación de las poblaciones andinas... Por lo tanto, Sarmiento cumplió el rol de vocero del Virrey, quien fue responsable de la reorganización y, más específicamente, de una nueva concretización ('reconcretización', en el caso de Pacariqtambo) hispano-inspirada de los pueblos y lugares andinos del temprano periodo colonial" (Urton, 2019. p. 16). Los aportes de los cronistas como Garcilaso de la Vega y de Guamán Poma, son notables en ese sentido, porque ellos utilizaron también fuentes orales quechuas, pero van más allá de los cronistas soldados o sacerdotes de la época de la conquista.

Por otro lado, se afirma que fue el idioma de los incas una lengua que se extendió desde el norte de Argentina hasta el sur de Colombia, abarcando los actuales territorios de Ecuador, Perú y Bolivia. En otras palabras, fue una lengua panandina que abarcó a otros países, y por otro lado, fue la lengua oficial en la época incaica pero no se originó con los incas ni exclusivamente en el espacio geográfico de su dominio: "En esta perspectiva sugería Torero que la costa central podía haber utilizado un protoquechua como idioma de relación con las regiones más altas. Mientras la costa sur utilizaba con el mismo carácter el protoaru y la costa norte el protoculle como lengua de relación. Allí en la costa norte habría un mayor desarrollo de las técnicas de navegación a larga distancia" (Macera, 2008. p.6). Según el estudio de Torero, como bien señala Macera (Op. Cit), el espacio de su origen básicamente estaba en la costa, en un conjunto de lenguas que pertenecieron a una familia lingüística ${ }^{(3)}$.

(3) "En los momentos de la invasión europea, la situación lingüística era bastante más compleja que en la actualidad. Se hablaba numerosas lenguas hoy desaparecidas. Si bien el quechua, el aimara, el puquina y el mochica, desempeñaban un papel articulador que hizo que los españoles las denominaran lenguas generales, paralelamente, coexistían otras lenguas como el culli, el quignam, el uru, el aru central y muchas otras hoy extinguidas, en proceso de extinción, o muy contraídas con respecto a sus territorios ancestrales". (Torero, 1974. p.240). 
Otro gran momento histórico que se suscitó con el idioma quechua fue la gran rebelión de Tupac Amaru en el periodo final del siglo XVIII. Si utilizamos la ley contrafactual la situación habría cambiado radicalmente. De haber triunfado: "el Cusco sería la capital del Perú, la sierra predominaría sobre la costa, los gobernantes descenderían de la aristocracia indígena colonial, el indio y su cultura no habrían sido menospreciados..." (Flores Galindo, 2008. p. 108). Perdimos esa oportunidad histórica y el idioma quechua quedó proscrito, legal y socialmente; junto a todos los signos de la cultura andina, porque eran una amenaza para la vigencia del dominio colonial.

Finalmente, desde la lingüística se han dado los aportes más significativos. Particularmente, Alfredo Torero hace innovaciones y sugerencias desde una perspectiva histórica, señalando dos derroteros históricos: i) atribuye que el origen de una variante de este idioma fue en Chinchaysuyo (en la región de la costa), cerca deloquefueel templo de Pachacamac;yii) yqueen los siglos IVyVyVI, los mercaderes venidos de otras zonas y regiones a dar culto a Pachacamac se encargaron de difundirlo a otras latitudes, surgiendo de esa manera las variantes de ese idioma en diferentes regiones del país: "El papel que Chincha cumplía en la canalización de este comercio era virtualmente irremplazable por su posición geográfica; de allí que su lengua, el quechua chinchay (IIB-C), se extendiera por el mundo andino como idioma de relación desde los primeros siglos del milenio actual. Puede postularse, entonces, que, aparte de su área de pleno dominio en la costa peruana central y sur y la serranía contigua a ésta, el quechua Chínchay empezó a penetrar en regiones muy distantes como lengua de relación adoptada por los señores y los mercaderes interesados en el comercio interregional andino y respaldada por el poder económico de Chincha y el ascendiente religioso y político de Pachacámac"(Torero, 1984. p. 6 y 43).

\subsection{Itinerario del quechua en el siglo XX}

De acuerdo a diversos estudios, se puede identificar hasta tres momentos cruciales en el siglo XX que dan cuenta del derrotero histórico del idioma quechua: Desde el inicio del siglo XX, hasta las primeras dos décadas, hasta 1924 con el gobierno de Leguía, el quechua era considerada "una lengua hablada por los indios", con muchos signos de menosprecio y de poca valoración. Como fruto e influencia del movimiento indigenista de esa época se recupera su valor histórico, su vigencia y su proyección. De alguna manera, el Estado trató de reivindicar esa condición, declarando el 24 de junio como día del indio y reconociendo a las comunidades indígenas como organizaciones sociales de raigambre histórica, pero manteniendo el racismo y la exclusión social.

El segundo momento de crucial importancia se da en el gobierno de Juan Velasco Alvarado (1968-1975) que reivindica y declara al quechua como idioma oficial(4), "encaminado a reorientar y rectificar el intercambio asimétrico entre los

De acuerdo a la Ley 211256 (27.5.1975) 
segmentos hispanohablantes y los segmentos quechua hablantes del Perú. Esto representa un intento de encaminar el quechua como una forma de situar en pie de igualdad la interacción cultural, cívica y política entre el grupo más occidental y más urbano, de una parte, y el menos occidentalizado y más rural, de la otra" (Escobar, 1976. p.11). En este periodo se organizaron eventos regionales, se da la reforma educativa dando prioridad para su difusión escolar, se discute y se reflexiona sobre la educación bilingüe, el local del Diario El Comercio se expropia y se entrega a la CNA (Confederación Nacional Agraria), organización agraria creada por la reforma agraria, entre otras acciones. No está demás mencionar que con este gobierno empieza la desaparición de la oligarquía peruana y el proceso de inclusión social de los campesinos. Desde esa fecha, la historia rural del país cambia inexorablemente.

El tercer momento se da a nivel de las políticas educativas del país (PozziEscot, 1991), en la década del 80 del siglo pasado (la Educación Bilingüe Intercultural (1980). Como antecedente se tiene el Sistema de Educación Bilingüe en la Selva $(1952)^{(5)}$, caracterizada por una educación dual (urbana/rural) que duró hasta la década del 70. En esa década se comienza a cuestionar esa forma de enseñanza; y se produce la primera Política Nacional de Educación Bilingüe (1972). En esa norma educativa, la discusión de fondo giró en torno al mantenimiento y la transición hacia las lenguas originarias. Recién en la reunión de Pátzcuaro (1980) se tiene una nueva denominación: educación bilingüe intercultural. En uno de los aspectos de la EBI establece un principio revolucionario: "De un lado, prescribe la educación bilingüe para todos los del habla vernácula; de otro, la educación intercultural, para todos los peruanos" (Pozzi-Escot,1991, p.143). Hoy en día contamos con una Política de Educación Intercultural Bilingüe (2015) que tiene como objetivo garantizar una oferta educativa que permita el logro de aprendizajes pertinentes y de calidad a los estudiantes de los pueblos originarios.

\section{El idioma quechua y los datos censales ${ }^{(6)}$}

Nuestro interés en esta parte es mostrar tres datos censales comparativamente (1993, 2007 y 2017), en los cuales se pueda percibir la evolución cuantitativa de personas quechua hablantes y la autoidentificación étnica entre un periodo censal a otro.

Según las fuentes oficiales (2017), el Perú tenía 3`799,780 hablantes que tienen al quechua como primera lengua (13.06\%). En el censo anterior (2007) se tenía $3 ` 360,331$ personas, lo que representaba el $13.02 \%$ en cifras relativas, respecto a la población total nacional.

(5) Colaboración del gobierno peruano con el Instituto Lingüística de Verano que trabajaba en el Perú desde 1945. (Pozzi -Escot. 1991. Pág. 21).

(6) Para esto tomamos en cuenta los aportes valiosos de Luis Andrade Ciudad ORCID: PUCP, Lima, Perú. Contacto: Ifandrad@pucp.edu.pe 
Como se podrá notar, de un censo a otro, se observa un crecimiento intercensal en cifras absolutas (el total de hablantes) y bastante leve en cifras relativas (la proporción de hablantes). No es un crecimiento notable, pero es un crecimiento y no un descenso. Este hecho es muy importante en términos relativos, porque pone en tela de juicio "los discursos hegemónicos que avizoran el irrefrenable proceso de debilitamiento y extinción de la lengua originaria"(7). Es allí la importancia y la refutación que hace Rodrigo Montoya a Richard Webb:

"Para unos, el quechua se pierde, es real; y para otros, el quechua se gana, se recupera, y hay una alegría enorme ante eso. Los cinco conos de Lima son un laboratorio del quechua, los sábados y domingos de todos los meses. Hay que ser ciego para no ver eso; pero eso no pasa por la televisión, ni las columnas de los periódicos. Entonces, pareciera que no ocurre. Hay una realidad subterránea. Todo lo propio, autóctono del país fue sometido, oculto. Ahora todo eso está haciéndose visible. Se hacen ofrendas a los Apus en todas partes... con la rabia de la Iglesia Católica que no sabe cómo contradecir eso, porque no tiene cómo. Le encantaría mandarlo de vuelta a las cavernas, pero no es posible. Entonces, hay una vitalidad, un florecimiento que no niega la vieja historia colonial de lo que se hace para que las lenguas se pierdan. $Y$ es ahí cuando aparece el fenómeno de la vergüenza. Porque hay gente que tiene vergüenza de ser peruana. Que le gustaría haber nacido en Grecia o en Miami, o en Europa. No estoy hablando de andinos ni serranos, estoy hablando de peruanos. Hay andinos y serranos (como cualquier otro peruano) que no se quieren porque les han enseñado a despreciar a los abuelos, los apellidos, los rasgos indígenas, y por lo tanto sufren. El Perú es un país dramático. Son fragmentos de lo que fue una gran civilización, una gran historia, que está ahí, en pequeños pedazos. Y de lo que se trata es de unir fragmentos para reconstituir algo que pueda llamarse una especie de honor o dignidad peruana. Entonces, eso que este señor lamenta, lo que le pasa a una familia quechua hablante, es la historia del país, es la herencia de Pizarro, y es la herencia de los grandes capitalistas y las grandes empresas multinacionales. Esta es la lógica del capital, de El Comercio y del mundo de Richard Webb" ${ }^{\prime \prime(8)}$.

La pregunta que queda es ¿cómo entender este ligero crecimiento o en el peor de los casos, mantenimiento de la proporción de quechua hablantes en el Perú?

(7) Ob. Cit." ¿Tiene futuro el quechua?": las opiniones de Richard Web: "El quechua es una lengua en peligro de extinción. En un lapso históricamente corto ha pasado de ser la lengua mayoritaria del país a ser el idioma de una pequeña minoría. En 1940, dos de cada tres peruanos lo hablaban. Hoy, apenas quince por ciento de la población dice haberlo aprendido en su niñez, y con seguridad muchos de ellos han dejado de practicarlo de adultos". Sobre la extinción del quechua no tiene argumentos sólidos ni conocimientos suficientes sobre el derrotero histórico de este idioma. Al respecto la refutación de Rodrigo Montoya es más que contundente.

(8) Opiniones y refutación de Rodrigo Montoya A R. Webb. https://redaccion.lamula.pe/2014/02/23/ richard-webb-no-sabe-nada-de-la-lengua-quechua/albertoniquen/ 
Podemos ensayar algunos argumentos que explican esos datos oficiales: por un lado, como efecto de las políticas dictadas desde el Estado y las acciones desarrolladas desde la sociedad civil en los últimos años para la vigencia y revaloración de las lenguas originarias; $y$ como efecto de las preguntas formuladas y aplicadas durante el censo sobre las lenguas originarias, "particularmente para el quechua y el aimara, la introducción de la pregunta sobre autoidentificación étnica en el último ejercicio censal"(Andrade, 2019).

En el primer caso, se puede mencionar las acciones llevadas desde el Ministerio de Cultura y, en particular, desde la Dirección de Lenguas Indígenas (DLI 22013); con la aprobación y aplicación de la Ley de Educación Intercultural Bilingüe. Añadimos las acciones hechas por la Defensoría del Pueblo (visibilización de las lenguas originarias); y las políticas lingüísticas regionales como, por ejemplo, la iniciativa «Quechua para todos» en la región Apurímac. Para el segundo caso, posiblemente la influencia que debió haber tenido la introducción de la nueva pregunta sobre autoidentificación étnica en las respuestas sobre autoidentificación lingüística (con la categoría «quechua»).

Cuadro No 1. Autoidentificación como quechua y autoidentificación lingüística

\begin{tabular}{|c|c|c|c|}
\hline \multicolumn{2}{|c|}{ Autoidentificación étnica quechua } & \multicolumn{2}{c|}{ Autoidentificación lingüística quechua } \\
\hline Total & $\%$ & Total & $\%$ \\
\hline $5 ` 176,809$ & 22,32 & $3^{`} 799,780$ & 13,6 \\
\hline
\end{tabular}

Fuente: INEI 2017b.

A partir de estos datos oficiales, se puede mencionar: i) que el quechua es la segunda categoría étnica más elegida en el Perú después de mestizo (13,965, 254 peruanos, que hacen el $60,20 \%$ de la población). Eso implica que, hay más personas en el Perú que se autoidentifican como quechuas que como blancos, aimaras, afroperuanos, nativos o indígenas de la Amazonía; y ii) que la cantidad y proporción de personas que se autoidentifican étnicamente como quechuas supera largamente la cantidad y proporción de personas que declaran tener al quechua como lengua materna.

\subsection{Departamentos con mayor densidad quechua}

En las siguientes líneas se muestra los diez departamentos con mayor densidad quechua en cifras relativas (1993, 2007 y 2017). Se observa la fuerza que aún tiene la lengua quechua, especialmente en los departamentos del sur y del sur central, donde la proporción de quechua hablantes supera el $50 \%$ de la población departamental (Apurímac, Huancavelica, Ayacucho y Cusco) y se sostiene a lo largo de cerca de 25 años (en el periodo de los tres censos nacionales). Madre de Dios aparece en los tres censos, y no parece una novedad, porque los procesos 
migratorios de otras regiones a esa región se dieron desde décadas anteriores (boom del caucho), por razones laborales y de extracción de productos tropicales.

\section{Cuadro N. ${ }^{\circ}$ 2: Diez departamentos con mayor densidad quechua hablantes del Perú:}

(Censos: 1993, 2007 y 2017)

\begin{tabular}{|l|c|l|c|l|c|}
\hline \multicolumn{1}{|c|}{ Regiones } & $\mathbf{1 9 9 3}$ & \multicolumn{1}{c|}{$\mathbf{2 0 0 7}$} & $\mathbf{\%}$ & \multicolumn{1}{c|}{$\mathbf{2 0 1 7}$} & $\mathbf{\%}$ \\
\hline Apurímac & 76.58 & Apurímac & 70.58 & Apurímac & 69.69 \\
\hline Ayacucho & 70.58 & Hvca. & 64.03 & Huancavelica & 64.29 \\
\hline Huancavelica & 66.48 & Ayacucho & 63.05 & Ayacucho & 62.47 \\
\hline Cusco & 63.23 & Cusco & 51.40 & Cusco & 54.32 \\
\hline Puno & 43.23 & Puno & 38.01 & Puno & 42.27 \\
\hline Ancash & 35.87 & Ancash & 31.36 & Ancash & 30.04 \\
\hline Huánuco & 30.78 & Huánuco & 28.56 & Huánuco & 27.94 \\
\hline Madre de Dios & 24.11 & M. de Dios & 16.53 & Madre de Dios & 18.46 \\
\hline Arequipa & 17.14 & Arequipa & 14.78 & Arequipa & 17.35 \\
\hline Junín & 12.58 & Moquegua & 9.57 & Junín & 13.12 \\
\hline
\end{tabular}

"Un segundo hecho llamativo, es que en algunos departamentos observamos un leve incremento en la densidad del quechua respecto a 2007 (Huancavelica, Cusco, Puno, Madre de Dios y Arequipa), aunque en otros se observa un leve descenso (Apurímac, Ayacucho, Áncash y Huánuco). El descenso más pronunciado se observa en Ayacucho, entre 1993 y 2007, lo cual probablemente se pueda correlacionar con los efectos del conflicto armado interno (migración compulsiva de la población rural hacia otros departamentos), ya señalado por la Comisión de la Verdad y Reconciliación en su Informe final" (Andrade, 2019).

Al final, crecimiento y descenso, un doble proceso en los departamentos con mayor densidad quechua, y las tendencias irregulares (descenso-crecimiento) que se observan en Junín, Cusco, Puno, Arequipa y Madre de Dios, tomando en cuenta la progresión de la densidad desde 1993.

\subsection{Lima y los distritos con mayor cantidad de quechua hablantes}

Hace años decíamos que el centralismo limeño también se daba con el proceso demográfico en el país, porque era el blanco de las migraciones. El censo de 2017 también nos muestra la presencia de hablantes del quechua en Lima. Al respecto mucho se ha mencionado el caso de San Juan de Lurigancho y el caso de Lima Norte como muestra de los efectos de la migración en la reconfiguración del contexto urbano y del paisaje lingüístico limeño. En efecto, este distrito sigue 
siendo el de mayor cantidad de quechua hablantes en el Perú, pero no es un caso aislado. Si miramos con mayor rigor los datos censales de los Distritos en la parte sur (Villa María, San Juan de Miraflores y Villa el Salvador), juntos hacen un 31.16\%, cifra altamente significativa. En todo caso, es más contundente afirmar que los diez distritos con mayor cantidad de quechua hablantes se ubican todos en la ciudad capital. No obstante, en estos distritos la proporción de quechua hablantes se ubica, en promedio, alrededor del $10 \%$ de la población total distrital.

Cuadro N. ${ }^{\circ}$ 3: 10 distritos de Lima con mayor cantidad de quechua hablantes

\begin{tabular}{|cl|c|c|c|}
\hline \multicolumn{2}{|c|}{ Distrito } & Región & Total & \% \\
\hline 1. & San Juan de Lurigancho & Lima & 107,214 & 10.83 \\
\hline 2. & Ate, & Lima & 63,885 & 11.20 \\
\hline 3. & Villa María del Triunfo, & Lima & 43,806 & 11.51 \\
\hline 4. & Puente de Piedra & Lima & 37,972 & 12.16 \\
\hline 5. & San Martín de Porres & Lima & 36,571 & 5.82 \\
\hline 6. & San Juan de Miraflores & Lima & 36,335 & 10.64 \\
\hline 7. & Villa El Salvador & Lima & 33,875 & 9.01 \\
\hline 8. & Comas & Lima & 29,261 & 5.88 \\
\hline 9. & Lurigancho & Lima & 28,466 & 12.45 \\
\hline 10. & Carabayllo & Lima & 27,711 & 8.77 \\
\hline
\end{tabular}

Fuente: INEI 2017b.

De estas cifras censales mostradas en los cuadros anteriores podemos ensayar algunas reflexiones:

- Los datos cuantitativos presentados sobre el quechua (los recientes datos censales sobre los totales y las proporciones demográficas relativas al quechua en el Perú), demuestran que no es posible ser contundente ni categórico para evaluar "los caminos de una lengua o, como sucede en este caso, de una familia lingüística, porque dichos caminos los construyen los hablantes y sus agrupaciones en medio de la historia" (Andrade. 2010).

- Deigual manera, se puede apreciar que hay regiones ozonas en los cuales el quechua se está manteniendo con mucha trascendencia y vitalidad, como por ejemplo en estas dos zonas delimitadas lingüísticamente: i) la zona este de Ancash (para el quechua I o huáihuash); ii) la zona de Yungay (quechua II), donde en los Departamentos de Apurímac, Huancavelica, Ayacucho y Cusco, se mantiene la lengua originaria vigente.

- A partir de los datos oficiales analizados sobre el quechua, existen dudas sobre la continuidad de transmisión de este idioma. Esas opiniones se dividen en dos: i) el discurso pesimista y fatalista que ve sin futuro, incompatibles con la modernidad y el desarrollo del país, 
pero se ve fuertemente cuestionado por la tendencia al crecimiento analizada; ii) la ruralización de las lenguas indígenas para el caso del quechua en Apurímac, puede ser desafiada con los resultados sobre la cantidad de hablantes en Lima Metropolitana.

- Reiteramos, Madre de Dios, ubicado en la región amazónica, es un Departamento con mucha historia en cuanto a los procesos migratorios hacia ese lugar; es uno de los diez departamentos con mayor densidad quechua desde el censo de 1993. Este hecho descarta las posiciones esencialistas que atan el quechua solamente a las geografías y entornos andinos y sin tomar en cuenta los procesos migratorios y la existencia de otros quechuas ("quichuas") amazónicos desde siglos atrás.

- Por último, vía los procesos migratorios, se puede observar la continuidad o la reproducción del quechua y del aymara en la Ciudad de Lima, en las últimas décadas del presente siglo.

\section{El problema inter generacional en la enseñanza del quechua}

En esta parte nos detenemos con mayor rigor en la reflexión y trataremos de abarcar la mayor cantidad de aspectos conectados con el idioma quechua. Para aproximarnos a los factores o razones que existen en forma abierta o implícitamente y que impiden la trasmisión del idioma quechua de una generación a otra, hemos elaborado un cuadro con 23 casos (conversaciones hechas con los migrantes ubicados en distintas regiones del país, y excepcionalmente en el extranjero). Esta forma de aproximarnos no es estrictamente una herramienta metodológica, sino un sondeo, un acercamiento, con la finalidad de obtener información de primera fuente que sirva para una reflexión mayor, articulando varios aspectos sociales concomitantes, de coyunturas pasadas y presentes. En su totalidad, son migrantes de primera generación ubicados en Cusco, Arequipa, Lima y otros lugares; algunos son personas que vivieron tres décadas en la ciudad de Cusco. La pregunta que se formuló fue: ¿Por qué quienes saben el idioma quechua no lo enseñan a sus hijos?”. Ver el siguiente cuadro:

Cuadro N4: ¿Por qué los padres no enseñan quechua a sus hijos?

\begin{tabular}{|c|c|c|c|c|}
\hline CASOS & $\begin{array}{l}\text { Padres } \\
\text { /saben } \\
\text { quechua }\end{array}$ & Residencia & Ocupación & ¿Por qué los padres no enseñan a sus hijos? \\
\hline Caso 1 & Si & Lima & Taxista & Trato de enseñar, pero mis hijos no toman interés \\
\hline Caso 2 & No & Lima & Musicóloga & $\begin{array}{l}\text { Un idioma desprestigiado durante siglos...los padres no } \\
\text { desean que sus hijos lo hablen porque ellos también serán } \\
\text { desprestigiados. }\end{array}$ \\
\hline Caso 3 & No & Cusco & Geógrafa & $\begin{array}{l}\text { Van a discriminar a sus hijos. No sirve para nada. Es un } \\
\text { idioma de indios, incultos }\end{array}$ \\
\hline Caso 4 & $\mathrm{Si}$ & Cusco & Bióloga & Por flojera, por dejadez. \\
\hline Caso 5 & $\mathrm{Si}$ & Cusco & Comercio & Trato de enseñar, pero los hijos no quieren aprender. \\
\hline
\end{tabular}




\begin{tabular}{|c|c|c|c|c|}
\hline Caso 6 & $\mathrm{Si}$ & Cusco & Contador & $\begin{array}{l}\text { Porque creen que el quechua es atraso; porque no quieren que } \\
\text { sufran como ellos; porque no sirve; otros dicen, para que no vaya } \\
\text { mis hijos a zona rural a trabajar. Es idioma de los indios..." }\end{array}$ \\
\hline Caso 7 & $\mathrm{Si}$ & Cusco & Biólogo & $\begin{array}{l}\text { "Que siempre se cree que el quechua es una lengua inferior, } \\
\text { y al que habla quechua lo hace inferior" }\end{array}$ \\
\hline Caso 8 & $\mathrm{Si}$ & Cusco & Antropólogo & $\begin{array}{l}\text { Es muy difícil aprender y hablar. } \\
\text { Por vergüenza, que dirán los demás, o sea el problema de } \\
\text { complejo de inferioridad } \\
\text { Por último, ahora los jóvenes creen que hablar quechua es } \\
\text { sinónimo de inferioridad }\end{array}$ \\
\hline Caso 9 & $\mathrm{Si}$ & Cusco & Historiador & $\begin{array}{l}\text { Además, creo que es nuestra realidad y forma parte de } \\
\text { nuestro problema. Solo piensa: es una lucha entre el día y } \\
\text { la noche; entre el que tiene ojos y el que no los tiene; entre } \\
\text { el que sabe leer y escribir y el analfabeto; entre la ciudad y } \\
\text { el campo; entre la puna y la qheswa; entre los que tienen el } \\
\text { apellido español e indígena...", }\end{array}$ \\
\hline Caso 10 & $\mathrm{Si}$ & Cusco & Antropólogo & $\begin{array}{l}\text { Siempre el problema es el prestigio asociado al idioma, por } \\
\text { eso tampoco las padres lo enseñan a sus hijos". }\end{array}$ \\
\hline Caso 11 & $\mathrm{Si}$ & Lima & Taxista & Yo trato de enseñar a mi hija. \\
\hline Caso 12 & $\mathrm{Si}$ & Cusco & Turismo & $\begin{array}{l}\text { Depende de los contextos. En zonas rurales, sí. En las } \\
\text { ciudades, no: aprender un nuevo idioma va más para poder } \\
\text { acceder a una oportunidad laboral o acceder a un título } \\
\text { profesional y es por ello que las familias no priorizaban en } \\
\text { enseñar la lengua. Discriminación existente: como en Lima } \\
\text { aún existe una discriminación a la persona que habla este } \\
\text { idioma sobre todo en las clases sociales C y D. }\end{array}$ \\
\hline Caso 13 & $\mathrm{Si}$ & Cusco & Enfermera & $\begin{array}{l}\text { Mi mama por el trabajo no pudo enseñarnos. Yo me acuerdo que } \\
\text { en casa hablaban en quechua y nosotras pedíamos en castellano. } \\
\text { Mi hermana mayor aprendió a hablar el quechua porque se } \\
\text { fue a vivir con mi abuelita al pueblo por un tiempo. }\end{array}$ \\
\hline Caso 14 & $\mathrm{Si}$ & Lima & Fotografío & Por discriminación a nivel familiar. \\
\hline Caso 15 & $\mathrm{Si}$ & Brasil & Médica & $\begin{array}{l}\text { No les enseñan por vergüenza. El idioma quechua cultural- } \\
\text { mente está relacionado a la pobreza, es un estigma ser pobre. }\end{array}$ \\
\hline Caso 16 & $\mathrm{Si}$ & Lima & Antropólogo & $\begin{array}{l}\text { No logra superar los traumas del conflicto indio misti. El } \\
\text { racismo aún está presente en las relaciones sociales y } \\
\text { humanas. Aún hay un racismo soterrado. }\end{array}$ \\
\hline Caso 17 & $\mathrm{Si}$ & Lima & Enfermera & $\begin{array}{l}\text { "porque el quechua dejo de ser nuestro idioma principal, hablamos } \\
\text { castellano. Vivimos en entornos donde se habla en castellano. }\end{array}$ \\
\hline Caso 18 & $\mathrm{Si}$ & Arequipa & PNP & $\begin{array}{l}\text { Por vergüenza. Pero cuando comenzó a valorarlo y darle su } \\
\text { ponderación no tenía paciencia para enseñamos. Unalástima por eso. }\end{array}$ \\
\hline Caso 19 & $\mathrm{Si}$ & Lima & Educadora & Por racismo y discriminación. \\
\hline Caso 20 & $\mathrm{Si}$ & Cusco & $\begin{array}{l}\text { Profesor } \\
\text { universitario }\end{array}$ & $\begin{array}{l}\text { Enseñé a mis tres hijos. En los otros casos: por vergüenza, } \\
\text { por esconder sus raíces, porque no sirve para trabajar, por } \\
\text { migración a tierna edad. }\end{array}$ \\
\hline Caso 21 & $\mathrm{Si}$ & Lima & $\begin{array}{l}\text { Profesora } \\
\text { Universitaria }\end{array}$ & $\begin{array}{l}\text {-Tal vez porque el uso social no está garantizado, } \\
\text {-Dominio poco fluido del quechua (padres). Se avergüenzan } \\
\text { de cometer errores en pronunciar. } \\
\text {-Hay la idea que si se aprende una lengua originaria y se la } \\
\text { usa cotidianamente uno se vuelve motoso, incompetente en } \\
\text { la expresión del castellano. } \\
\text {-Los jóvenes y niños tienden a burlarse de los padres cuando } \\
\text { hablan en quechua, los tachan de poco modernos. }\end{array}$ \\
\hline
\end{tabular}




\begin{tabular}{|l|l|l|l|l|}
\hline Caso 22 & Si & Lima & Actor teatral & $\begin{array}{l}\text {-Como militantes de izquierda nos hemos colonizado y hemos } \\
\text { hipotecado aspectos ideológicos, políticos, culturales y religiosos. } \\
\text {-Una consecuencia ha sido el olvido de los espacios } \\
\text { familiares. } \\
\text {-En nosotros habita un desprecio por el idioma, pero no se habla. } \\
\text {-Hay una autocensura, problema de autoestima y de } \\
\text { discriminación. }\end{array}$ \\
\hline Caso 23 & & Lima & psicóloga & Por vergüenza \\
\hline
\end{tabular}

Fuente: Elaboración propia. 28.2.2020.

Del cuadro anterior extraemos aspectos explicativos que influyeron en la no enseñanza de este idioma de padres a hijos/as:

En primer lugar, los resultados no son novedosos en la mayoría de los casos, pero sí sorprendentes en algunos de ellos. De ese universo total (23), apenas en un caso se nota con claridad, una convicción y una identidad definida con la cultura andina, cristalizada en la enseñanza del idioma quechua de padres a hijos. En los siguientes dos casos (migrantes recientes a Lima), procuran o intentan realizar la enseñanza a sus hijos.

En segundo lugar, en lo que atañe al idioma quechua, subrayamos que no es solamente un problema coyuntural ni circunstancial, es un problema de largo aliento. Desde una visión retrospectiva, forma parte de un problema mayor de la nación peruana: heredamos desde la época colonial distancias culturales, estereotipos sociales y exclusiones permanentes. En realidad, se constituye como un problema abarcativo e integral de la realidad peruana. Como bien lo menciona una entrevistada, el idioma quechua ha sido tan desprestigiado durante siglos, que los padres no desean que sus hijos hablen quechua, porque piensan que ellos también serán desprestigiados ${ }^{(\mathbf{9})}$.Otra entrevista realizada, resume esa situación señalada y apunta con mayor amplitud a esa noción abarcativa: es como la lucha entre el día y la noche; entre el que tiene ojos y el que no tiene; el que sabe leer y escribir y un analfabeto; entre la ciudad y el campo; entre la puna y la qheswa; entre los que tienen el apellido español e indígena...(10).

En tercer lugar, en ese itinerario a largo plazo, la distorsión de su proceso de continuidad y vigencia se evidencia también con la instalación de las escuelas rurales en el país, desde comienzos del siglo XX hasta la actualidad: El lenguaje familiar contrasta con el que la escuela propone: otra lengua, diferente, totalmente excluyente:

"De acá se deriva que, para colocar a los estudiantes en idénticas oportunidades frente a la sociedad, la escuela debe trabajar en los años primeros procurando compensar tan acusado desnivel. No es tarea fácil, y no alcanza a disimular (ni a vencer) la dificultad el énfasis de los

(9) Entrevista a Flor Canelo. Cuaderno de campo.

(10) Una conversación alentadora con el Dr. Donato Amado. 
partidarios de la innovación. Es que el atropello y la exaltación no son armas convincentes. No es tarea fácil porque el ambiente familiar no se modificará con el mismo ritmo con que ha de trabajar la escuela. Y si esto es cierto en países desarrollados como Inglaterra, lo es, en grados más elocuentes, en los países que viven en pleno desarrollo" (Escobar, 1976-b).

En cuarto lugar, otro aspecto concomitante al idioma quechua, desde la sociedad civil, desde la visión del Estado (oligárquico, moderno e incluyente), desde las instituciones privadas, desde los servidores públicos en todas los niveles e instancias, es que las comunidades campesinas son consideradas como instituciones de menor rango, de poco prestigio y sin ninguna posibilidad de acceder a las entidades financieras, por eso fácilmente se las etiqueta como "sujetos sin crédito". Con el avance del proceso de modernización han sido obligadas a refugiarse y actuar a la defensiva, a contracorriente de ese proceso.

En quinto lugar, las instituciones educativas se engarzaron por encima de esas instituciones de largo aliento histórico, que dieron los cimientos de una identidad nacional, con el objetivo de incluirlas canteras de la civilización y con pretexto de su asimilación a la modernidad. En consecuencia, la educación implementada hasta la década de los 80 , no fue para que se quedaran en sus lugares de origen, sino para sacarlas de allí, para generar una expulsión demográfica masiva. De esa manera, esas instituciones educativas se convirtieron en las grandes fábricas de migrantes del campo a las grandes ciudades. Desde luego, los profesores que llegaron a esos contextos quechua hablantes fueron vistos como apóstoles de la modernidad, afirmando entre otros aspectos que las nociones de patria, progreso, ciudadanía, bienestar, no estaban ancladas en áreas rurales sino en las grandes ciudades; en consecuencia, la idea era ir en su busqueda, salir de la oscuridad a la luz, una metáfora magistralmente utilizada por Rodrigo Montoya. Concluyo esta parte mencionando un caso que se relaciona con lo que describimos líneas arriba: en una promoción de una escuela primaria en una comunidad (1990), preguntamos a los 10 alumnos que pronto dejarían la escuela: ¿qué querían ser al abandonar la escuela? El 90\% respondieron diciendo: querían ser policías, profesores, médicos, enfermeras, etc. Solo un alumno dijo quedarse en la comunidad, comprarse un tractor y mejorar el trabajo en las chacras.

En sexto lugar, según las cifras censales, el proceso migratorio masivo y continuo de mayor alcance del campo a la ciudad se inició en la década del 40 del siglo pasado. Sin duda, estamos frente a un proceso que evidencia la disminución de la ruralidad y el incremento de la dinámica intercultural entre campo y ciudad, la presencia cada vez más fuerte de los medios de comunicación, que fortalece la presencia de la cultura urbana y esto que llaman y estandarizan los comunicadores como la «cultura universal». 
"Algo más, los padres de los chicos de familias originariamente quechua hablantes que están hoy en la escuela son, en buena medida, hijos de tercera o cuarta generación, son castellanohablantes y han aprendido que las oportunidades de progreso económico están fundamentalmente en las ciudades, lo que puede hacerles ver como natural que sus hijos se alfabeticen en castellano y no en el idioma nativo de sus padres o abuelos"(11)

De esos factores generales descritos y analizados, pasamos a un nivel más específico, en el que enumeramos los otros aspectos que aparecen en el cuadro anterior, que van a contracorriente del idioma quechua:

- El quechua ya no es el lenguaje de la casa ni es el idioma franco que se hablaba todos los días. Los hijos/as nacen con otro idioma, oficial y dominante. Escribir y hablar quechua se les hace difícil a los hijos de los migrantes, tan igual que otros idiomas existentes.

- El segmento de migrantes ubicados en los contextos urbanos piensa y cree que el quechua está asociado al atraso y la pobreza, lo contrario a la modernidad. Cuando se publicó Gregorio Condori Mamani en la década del 70 (Valderramay Escalante, 1976) ${ }^{(12)}$, los analistas sociales se dividieron en dos corrientes: aquellos que pronosticaban la bancarrota de la cultura andina; y aquellos que postulaban su continuidad. Con la reforma agraria de Velasco Alvarado (1969) sucedió lo mismo: el desarrollo pleno del capitalismo y el ocaso de las comunidades campesinas. No obstante, pese a esos escenarios, el quechua quedó vigente y las comunidades campesinas de largo aliento histórico siguen funcionando. Convendría anotar la siguiente idea vinculada a los migrantes:

"en el caso de la segunda y tercera generaciones (hijos y nietos de la primera), la cultura quechua tiende a perderse y solo se reproduce fragmentariamente, cuando los hijos y nietos a pesar de no hablar la lengua se identifican con la cultura; particularmente con la música, el canto, la danza y la espiritualidad» (p. 541), pero dicha identificación parcial no garantiza la reproducción cultural de la matriz andina" (Andrade, 2010. p.3).

- Otro aspecto casi generalizado está relacionado a la poca utilidad que tiene el idioma quechua para lograr un puesto de trabajo. Sin duda alguna, este idioma no es un requisito en términos laborales en el periodo contemporáneo, aunque esa situación haya cambiado relativamente en los últimos años. La opción inmediata en la mentalidad de los padres (migrantes), es que sus hijos aprendan otro idioma más atractivo, no solo para el trabajo, sino para alcanzar estudios superiores

(11) Entrevista a Luis Guerrero Ortiz, consultor especializado en temas educativos. Lima, febrero del 2020.

(12) La autobiografía de Gregorio Condori Mamani. Un cargador bultos, quechua hablante en Cusco, publicado por el CBC 
y la posibilidad de viajar al extranjero: "En las ciudades... aprender un nuevo idioma va más para poder acceder a una oportunidad laboral o acceder a un título profesional y es por ello que las familias no priorizaban en enseñar la lengua"(13).

- En la mayoría de los entrevistados se aprecia la existencia del racismo y la exclusión social, expresados de muchas maneras. Sumado a lo anterior, es probable que -si no hay una identidad históricamente afianzada y socialmente reconocida- el idioma nativo quede aún más arrinconado a espacios domésticos y marginales. Creo, en efecto, que hay detrás un problema de discriminación remarcada: a casi 20 años de la edición del libro de Portocarrero (1993), todavía están vigentes sus afirmaciones para el siglo XXI:

"Presumo que las razones de esta situación son evidentes: la dominación étnica, el racismo, genera un conflicto, a veces latente y disimulado, otras, abierto, y sanguinario. $Y$ aunque la fisonomía y la composición de los grupos en pugna haya cambiado mucho en el transcurso de la historia, todavía se mantienen vigentes patrones de interacción de clara estirpe colonial" (Portocarrero, 1993. p.9).

- Reiteramos, muchos de los estereotipos sociales asociados a este idioma que heredamos desde la época colonial hasta el día de hoy; rebasa los contextos locales, abarca a otros hechos sociales y tiene una connotación personal, local, regional y nacional. De esa manera, se desprenden con mucha facilidad, palabras y términos negativos en relación a los portadores de este idioma, en forma permanente y de alto contenido social explosivo. De ese universo de casos que anotamos en el cuadro anterior, enumeramos esos términos peyorativos: "desprestigio", "inferior", "cultura inferior", "discriminación", "idioma de indios", "de incultos", "atraso", "una lengua inferior y al que habla lo hace inferior", "vergüenza", "sinónimo de inferioridad", "por conservar el prestigio no se enseña a los hijos", "el estigma de ser pobres", "representa el conflicto misti/indio", "el racismo abierto o soterrado".

\section{Una introspección necesaria: el derrotero del quechua.}

En esta parte del ensayo, es importante volver a nuestras historias personales, a las batallas cotidianas por mantener la primera lengua (quechua) (Cornejo Polar, 1974). Iniciaré nombrando mi paqarina ${ }^{(14)}$ : nací en febrero loco (así decía mi padre porque en ese mes llovía a cántaros), en una comunidad ubicada a 3,200 msnm, en la zona quechua, donde florece la retama, el chiwanway y el t ankar (Sanka). El origen de mi pueblo está fechado en la época colonial, a la política de las reducciones en tiempos del Virrey Toledo. Pero antes era parte de un grupo étnico

(13) Entrevista: Caso 12.

(14) Esa palabra en quechua significa "lugar de origen". 
grande y notable, el de Hatun Papres, quienes fueron desplazados a la margen derecha del rio Apurímac, por la llegada de otro grupo proveniente de la región del Collao (los Chilques), hoy convertida en la comunidad de Araypallpa. Todos estos hechos históricos están vinculados a los mitos fundacionales de Cusco y su entorno.

Toda mi familia, desde mis tatarabuelos somos quechua hablantes. Soy el menor de ocho hermanos y cuando los mayores se hicieron jóvenes, se fueron a todas partes. Eso me incluye a mí también. Muy poco (un año), me quede a cuidar a mis padres, hasta que un hermano mayor regresó de Lima por mandato de otro hermano mayor, y mi padre para que no se escapara, le buscó una mujer joven para que se case. Tuvieron varios hijos/as, y todos ellos se fueron, como nosotros, a otros mundos y lugares.

Cuando mis hermanos mayores iban a la escuela, yo iba siguiéndolos, probablemente llorando. Allí aprendí el castellano, sin ser matriculado formalmente en la escuela primaria. De esa manera soy bilingüe desde entonces y tengo compañeros de promoción que son mucho mayores que yo. De esa época recuerdo tres pasajes, memoriales visuales pero notables al mismo tiempo: i) el lugar que ocupaba la escuela se llamaba "Alfacancha" (cancha de la alfalfa), probablemente era propiedad de un vecino notable (quizás él no era del pueblo), donde la gente acostumbraba a sacar ovejas y chivos de sus corrales para que se solearan en las épocas de lluvia. Por eso mis primos mayores y otros hombres letrados de ese tiempo nos decían despectivamente: "esos son apenas de Alfacancha"; ii) nuestra profesora era la esposa del hacendado (la hacienda Lloclla), y la aparición de su esposo en la escuela se daba de vez en cuando, como el arco iris en el cielo: sorpresivo y en completa soledad ${ }^{(15)}$; y iii) el hijo único de dicho hacendado, después de salir de la escuela iba montado a caballo a su hacienda, al centro, acompañado de otro niño quechua hablante de Sanka, que era su cuidante y fungia de compañía del niño Jorgito.

Nunca antes me había hecho esta pregunta, pero ahora es necesaria hacerla: ¿Qué tan importante era la escuela en ese tiempo? Seguramente que esa valoración excedía a las expectativas de la población local. Creo que es necesario recuperar varios aspectos de esas visiones que había en el escenario local: i) el prestigio que daba esa labor a los profesores; ii) el hecho de saber leer era mucho más importante que hablar quechua; y iii) se estudiaba para ser alguien. Esta última frase obviamente remite a una exclusión considerable de la mayoría de la población iletrada o quechua hablante. Una anécdota viene al caso: los primeros

(15) Esa hacienda fue el regalo que le hizo José Ángel Escalante, dueño del diario El Comercio, parlamentario por muchos años en la época del gobierno de Leguía, defensor de los indígenas en la esfera de dicho gobierno. El señor Latorre era dueño de la hacienda Lloclla, se había casado con la hija de J.A. Escalante, pero ella lo había abandonado estando casada por otro hombre. Para que no hubiera escándalos y problemas mayores, le regalo dicha hacienda, con ocho hombres traídos de la zona de Chumbivilcas. 
migrantes que se fueron, mandaban sus cartas por correo, y cuando estaba llegaba a su destino final, sus padres, no sabían leer, entonces se dirigían con súplicas a las casas donde sí sabían leer y hablar castellano (los vecinos) ${ }^{(16)}$. Durante la lectura y de acuerdo a la interpretación en quechua y tono que daban a sus voces, se alegraban o lloraban. Sus emociones también dependían de los lectores de la carta.

Terminé la educación primaria en la ciudad de Acomayo. La plaza principal estaba bajo el dominio de los hacendados, vecinos y autoridades. Muchos de ellos eran dueños de las tiendas de abarrotes, camiones de carga y pequeñas fincas en el entorno de la ciudad. En todo caso, predominaba en todo el ambiente la ideología gamonal y mucho de racismo. Un recuerdo visual muy grave fue este pasaje: un campesino de Chumbivilcas estaba ebrio, hablaba solo y en ese preciso momento vio a un profesor con terno, sentado en una de las bancas de la plaza: le increpó en quechua por su falta de dedicación a los alumnos, el profesor se paró de inmediato de su asiento y le dio una patada artera y el hombre cayó al piso de cemento, nadie lo auxilió ni el policía que estaba al costado. Igual pasaba con quienes iban de las comunidades a la feria dominical de esta pequeña ciudad: los policías los apresaban en grupos para que barran las calles principales de la ciudad, y no pasaba nada.

Un día cualquiera, inicié mi viaje a las ciudades. Tuve la despedida de mi padre, cuando clareaba un nuevo día, y yo arrodillado en un cemento frio para que me diera su bendición, hablándome en quechua y rezando entre dientes. Desde luego, la meta era llegar a Lima. No conocía las ciudades y me asustaban algunos de sus aspectos. Pasé por Cusco como un desconocido y me embarqué en un bus viejo hacia Lima. En los tres días que duró el viaje, hablé en quechua todo el tiempo, mi sorpresa mayor se produjo cuando el bus bajaba a media noche cerca de las laderas del volcán Misti, en la oscuridad me desperté de sorpresa y miré hacia abajo, donde se suponía que había una quebrada y una pampa en la que vi muchas luces de colores como esparcidas. Yo creí en ese momento que el cielo se había volteado, y que las estrellas del cielo estaban en el suelo desparramadas como los granos de un tierno choclo, todo eso se lo dije en quecha a mi hermano, $y$ él me respondió con un codazo en el estómago, con estas palabras: "eres un zonzo, esa pampa es la ciudad de Arequipa". Desde ese momento, para mí la ciudad era un mundo al revés.

Llegando a Lima, mis hermanos mayores me dieron tres meses para aprender el castellano y postular a un colegio nacional. Esa era la única condición para permanecer en esa Ciudad. No tuve más remedio que salir a la calle, ir a los parques a jugar y pelear con los chicos que no conocía. Seguramente mi castellano

(16) Ese término era asignado exclusivamente a los encomenderos en la etapa temprana de la época colonial. Su difusión masiva ocurre a partir del siglo XIX. Al término vecino se le asigna atributos como éstas: tiene educación, saber hablar castellano, atiende a las autoridades provinciales, tener buena casa, que aloja a los visitantes y tener buen apellido. 
era tan primitivo para ellos, por eso peleaba muy seguido. Llegado el plazo, postulé al colegio nacional y logré ingresar. Allí, con otros chicos venidos de otras partes del país, tuve una convivencia conflictiva, jerarquizada y estereotipada, especialmente complicada en los primeros años de mis estudios secundarios. Conviene narrar un incidente ocurrido a la hora del recreo, cuando tocaron la campaña, todos querían salir corriendo, éramos cuarenta alumnos empujándonos los unos a los otros por la puerta de salida que era pequeña, de pronto, alguien me metió el dedo en el ojo, y de inmediato grité en quechua: ñawiytanwiquruwanku" (me han metido el dedo en el ojo), entonces todos mis compañeros voltearon para saber quién había hablado y en qué idioma había hablado. A pesar de todo, logré estar en el último año en el cuadro de honor de los alumnos que salían del colegio.

El siguiente paso era la universidad. La obsesión personal era entrar a San Marcos, porque mantenía una fama universitaria en mi familia. Logré entrar y estudié sociología "para cambiar el país" como decían los dirigentes universitarios de esa época. En ese escenario el país aparece como problema y como posibilidad de cambio, la coyuntura de ese momento se encontraba marcada por la militancia partidaria, el triunfo de la revolución cubana, las guerrillas de Hugo Blanco en la Convención y Lares, la figura de Javier Heraud y el Ejército de Liberación Nacional, y el gobierno de Velasco Alvarado y la reforma agraria (1969). El quechua ya no era un idioma franco (de todos los dias), ni expresivo como en las primeras fases de mi vida. Aquí entro en el reino de las reflexiones conectadas a los problemas del país. Al terminar la etapa universitaria, vienen las grandes decisiones y una pregunta acuciante me formulaba: ¿a dónde ir y dónde trabajar? Opté por quedarme en el país y trabajar en las áreas rurales, para de esa manera recuperar el idioma quechua. Viajé casi por todo el país, conocí y hablé las variantes del quechua en Huancavelica, Ayacucho y Junín, luego en Cajamarca (La granja Porcón), por cierto, la segunda universidad para mí fue el periodo de la reforma agraria. Es en ese tiempo que conocí de verdad a los hacendados tradicionales, a los pongos de hacienda, a los campesinos sin tierra y sin historia.

En mi caso, al cambiar la residencia habitual que tenía antes (la aldea rural) a un contexto urbano (ciudad), en mi ciclo de vida aparece la familia y los hijos, quienes obviamente nacen con el idioma castellano como primera lengua. La situación es al revés en relación a los padres (mi caso). Añádase a esa situación, que la enseñanza del quechua es absolutamente informal y no escolarizada (no hay horarios, no hay días fijos, entre otros aspectos). Las prioridades son otras: ingreso familiar, educación de los hijos, formación profesional, responsabilidades laborales, viajes fuera del país, etc. La continuidad de la transmisión del idioma quechua se suspende, se rompe la cadena y la identidad cultural de los padres se multiplica, adquiere e incorpora otros elementos a los que habíamos aportado hasta entonces. En la época anterior, el quechua era una lengua de casa; ahora, no. 
Desde luego, mucho tiene que ver con la militancia política que habíamos tenido. Desde una mirada retrospectiva, el segmento de la población quechua hablante con una militancia política (desde una corriente "progresista"), para hacer trincheras de cambios sociales en el país, dejó de lado el idioma de sus orígenes y se olvidó explícitamente de las esferas familiares; de esa manera, se autocolonizaron con otros ideales y como consecuencia, hipotecamos muchos aspectos tan importantes, incluido el idioma. Una entrevista grafica explícitamente este escenario que describo de mi historia personal:

"...como militantes nos hemos colonizado y hemos hipotecado aspectos ideológicos, políticos, culturales y religiosos. Una consecuencia hasido elolvido de los espacios familiares, incluidos el idioma. En nosotros habita un desprecio por el idioma, pero no se habla explícitamente sobre esa situación, más bien se esconde. Hay una autocensura, un problema de autoestima y de discriminación"(17).

De esa manera, se mutiló un aspecto importante de nuestra subjetividad e identidad, por otro lado, sospecho que es una lengua de inconformidad en el subconsciente colectivo.

Ahora, recién en el siglo XXI, la existencia de mis hijos (Illari, Inti y Lucía), cuando a veces, mi hija me reprocha en quechua con estas palabras: "imanaqtinmi shayna millay kanki" (porque eres así tan malo), estoy con la gramática quechua en la mano, enseñándoles en forma coloquial y lúdica. Y los logros que van teniendo son clarísimos como el cielo abierto.

\section{A manera de balance y retos a futuro}

Escribo estas líneas desde el corazón de la Amazonía, cerca de los ríos Huallaga, el gran Marañón, Pastaza y Morona, después de haber recorrido 18 horas de viaje por esos ríos. Estoy en la provincia de Datem Alto Marañón, de la región de Loreto. Me voy muy temprano a recorrer la plaza central, allí encuentro un monumento dedicado a la figura de un líder indígena nativo de la amazonia. Como decoración, en un pasaje de la plaza están las características de los ocho grupos étnicos que habitan esa zona. Uno de esos grupos son los quechuas. En uno de los muros se puede leer estas oraciones: "...los pueblos quechuas no tienen otras denominaciones, sí un conjunto de identidades, entre las que se encuentran: Cañaris, Chancas, Chopccas, Huancas, Huaylas, Kana, Q'eros, que tienen como idioma materno el quechua en sus distintas variedades...Juntas estas poblaciones constituyen una parte mayoritaria de la población indígena del Perú". Muchos de los cuales son los antepasados de los actuales pueblos, con mitos y lugares de origen diferenciados.

(17) Entrevista Caso 22. Cusco, marzo del 2020. 
Sobre el futuro del Quechua, Rodrigo Montoya propone dos tendencias en pugna: i) apunta a la desaparición de la cultura quechua como consecuencia de la historia colonial y republicana, en contextos internacionales y nacionales adversos; y ii) "que se orienta a su reproducción y desarrollo relativamente autónomo, si es que triunfan los movimientos indígenas de Bolivia y Ecuador, y si en Perú los quechuas decidimos organizarnos políticamente para defender nuestros derechos al lado de los pueblos aimaras y amazónicos". (p. 557). "Es más, en el caso peruano, se trata de remontar una serie de procesos percibidos como adversos como la expansión del castellano, la caída del 'monolingüismo indígena' y la 'guerra religiosa' emprendida por las sectas protestantes" (Montoya, 2010. p. 558). Nosotros nos adherimos a la segunda tendencia porque tiene un horizonte histórico inocultable.

Sin embargo, a partir de los testimonios recogidos para este ensayo (casos), creemos importante resaltar algunos aspectos que dan cuenta de los problemas que afronta el quechua para su continuidad:

- Una tarea que se hace cotidiana y persistente es la de fortalecer la autoestima de la gente quechua hablante y convencer a la gente hispano hablante de la importancia del idioma quechua. En todo caso, estamos hablando de preservar en primer lugar, la identidad cultural como en Ecuador y Bolivia, o en la Amazonía peruana (de pertenecer al grupo étnico determinado: aguajun, shipibo, ashwar). En el último censo nacional (2017), se mencionaba la autoidentificación quechua étnica, con resultados sorprendentes si los comparamos con los que hablan solo este idioma; por eso es menester insistir en este aspecto. Por ejemplo, cuando se habla de identidad nacional en el Perú, se pone en tela de juicio ese concepto, "porque es una construcción mental, una ilusión verosímil...una carga valorativa...porque exige "identidad nacional" compartido por todos los individuos integrantes de una nación"...lo que existe es la idea compartida de formar parte de algo que se llama nación peruana" (Vergara, 2018. p. 118-119). Como reto queda una lucha frontal contra la discriminación (el racismo) y transformar esa base nacional en una comunidad política que trascienda los colores primarios que otorga la Nación. Lo mismo debería pasar con la identidad de ser quechua hablante, en todos los tiempos y en todos los universos posibles.

- El idioma quechua ya no es una lengua franca (hablada todos los días) ni un idioma de casa (en la versión de los campesinos), como lo fue en las décadas anteriores en los contextos rurales. Ahora es casi secundario y sólo aflora en ciertas ocasiones especiales. Los hijos/as nacen con otro idioma, oficial y dominante. Escribir y hablar quechua se hace difícil para los hijos de los migrantes, al igual que otros idiomas indígenas existentes; $y$ la enseñanza hacia ellos pasa por una enseñanza informal (sin gramática, sin horarios y sin horizonte alguno). 
- Sin duda alguna, el quechua no es un requisito en términos laborales en los tiempos contemporáneos, aunque esa situación haya cambiado relativamente en los últimos años. La opción inmediata es que aprendan otro idioma más atractivo, no solo para el trabajo, sino para alcanzar estudios superiores y la posibilidad de viajar al extranjero: en los contextos urbanos aprender otros idiomas tiene ciertas ventajas comparativas como acceder a una oportunidad laboral o acceder a un título profesional. Quizás, detrás de toda esta mirada esté la conquista de la ciudadanía en todos los espacios.

\section{Referencias}

AMES, Patricia, (2002). Para ser iguales, para ser distintos. Educación, escritura y poder en el Perú. Colección mínima. IEP. Lima.

ANDRADE, Luis, (2019). Dieznoticias sobre el quechua en el último censo peruano. PUCP. Lima.

ANDRADE CIUDAD, Luis (2010). Comentarios al libro de Rodrigo Montoya: Porvenir de la cultura quechua en Perú. Desde Lima, Villa El Salvador y Puquio. Lima: Fondo Editorial de la Universidad Nacional Mayor de San Marcos.

ANSIÓN, Juan, (2007). Educar en ciudadanía intercultural. Edit. Fondo Editorial PUCP. Lima.

BLÀCIDO, Ruth, (2016). La situación del quechua en el Perú y su inclusión en el sistema educativo. En: Universidad de Lima, Facultad de Comunicación (Ed.), Concurso de Investigación en Comunicación. 9na. Edición (pp. 230-242). Universidad de Lima.

CERRÓN PALOMINO, Rodolfo, (1991). Sobre el uso del alfabeto oficial QuechuaAimara. En: En: Madeleine, Zúñiga y otros: Educación bilingüe intercultural. Reflexiones y desafíos. Edit. FOMCIENCIAS. Lima.

CORNEJO POLAR, Antonio, et al, (1984). Vigencia y universalidad de José María Arguedas. Editorial Horizonte. Lima.

CORNEJO POLAR, Antonio, (1974 ). Los universos narrativos de José María Arguedas. Buenos Aires: Losada.

CHIRINOS, Andrés, (1998). Las lenguas indígenas más allá del 2000. Revista Andina N. ${ }^{3}$ 32. CBC - Cusco

ESCOBAR, Alberto, (1976). Introducción a la Gramática Quechua/Ayacucho/Chanca. En: Soto Ruiz, Clodoaldo: Gramática Quechua/Ayacucho/Chanca. IEP. Lima.

Escobar, Alberto (1976-b). Prologo a la Gramática Quechua/Ayacucho/Chanca de Clodoaldo Soto Ruiz. Edit. IEP.

FLORES GALINDO, Alberto (2008). Buscando un inca. Identidad y utopía en los andes. Edit. IAA. 
IDL. "Sobre el quechua y la ciudadanía en el Perú". Ideele Revista N. 239

DEGREGORI, Carlos Iván, (1991). Educación y mundo andino. En: Madeleine, Zúñiga y otros: Educación bilingüe intercultural. Reflexiones y desafíos. Edit. FOMCIENCIAS. Lima.

MACERA, Pablo, (2009). Alfredo Torero, un gran peruano del Siglo XX (viernes 14 de agosto de 2009). Edit. Libros \& Artes, N. ${ }^{\circ} 26-27$, Revista de cultura de la Biblioteca Nacional del Perú. Lima.

MONTOYA, Rodrigo, MONTOYA, Luis y MONTOYA, Edwin, (1987). Urqukunapayawarnin. La sangre de los cerros. Mosca Azul Editores, CEPES y la Universidad Nacional Mayor de San Marcos.

MONTOYA, Rodrigo, (1987). La cultura quechua hoy. Edit. Hueso Húmero. Lima.

MONTOYA, Rodrigo, (2010). El porvenir de la cultura quechua en Perú. Desde Lima, Villa El Salvador y Puquio. Lima: Fondo Editorial de la Universidad Nacional Mayor de San Marcos.

PORTOCARRERO, Gonzalo, (1993). Racismo y mestizaje. Edit. SUR Casa de Estudios del Socialismo. Lima.

POZZI- ESCOT, Unes, (1991). Ideas y planteamientos propuestos en el desarrollo y debate de la educación bilingüe en el país. En: Madeleine, Zúñiga y otros: Educación bilingüe intercultural. Reflexiones y desafíos. FOMCIENCIAS. Lima.

TORERO, Alfredo, (2002). Idiomas de los Andes. Lingüística e historia. Lima: Instituto Francés de Estudios Andinos/Horizonte.

TORERO, Alfredo, (1974). El quechua y la historia social andina (1974). Lima, Universidad Ricardo Palma.

TORERO, Alfredo, (1984). El comercio lejano y la difusión del quechua. El caso del Ecuador. Revista Andina, 2(2), 367-402.

TAYLOR, Gerald, (1999). Ritos y tradiciones de Huarochirí. IFEA. Lima.

TAYLOR, Charles, (1993). Elmulticulturalismoy "la política del reconocimiento". FCE. México.

VERGARA, Alberto, (2018).¿Hayidentidadnacionalenel Perú?pp. 118-123.En:Ciudadanos sin república. De la precariedad institucional al descalabro político. Planeta. Lima.

URTON, Gary, (1989). La historia de un mito: Pacariqtambo y el origen de los Inca. Revista Andina N.o 1. CBC - Cusco.

WEBB, Richard (2014). ¿Tiene futuro el quechua? Publicado en el diario El Comercio (10.2.2014).

VALDERRAMA FERNÁNDEZ, R., \& ESCALANTE GUTIÉRREZ, C. (1977). Gregorio Condori Mamani: autobiografía. Biblioteca de la Tradición Oral Andina, CBC. 